and, perhaps, a few with pure meningoceles rather than myelomeningoceles.

Our findings have prognostic implications. Neonatally it is impossible to be certain of sacral motor sparing but conus reflexes are readily demonstrated and so also is sensory sparing by general arousal to perianal pinprick. No matter how slight the neurological deficit otherwise, neuropathic bladder is virtually certain in an infant with negative conus reflexes or a sensory complete cord lesion. By contrast, one with a combination of positive conus reflexes and a sensory incomplete cord lesion may ultimately prove to have normal bladder and bowel control.

1 Brereton RJ, Zachary RB, Lister J. Urinary continence in open myelomeningocele. Arch Dis Child 1977;52:703-7.

2 Eckstein $\mathrm{HB}$. Urinary control in children with myelomeningocele. Br f Urol 1968;40:191-5.

3 Lorber J, Salfield WA. Results of selective treatment of spina bifida cystica. Arch Dis Child 1981;56:822-30.

4 Lorber J. Spina bifida cystica: results of treatment of 270 consecutive cases with criteria for selection for the future. Arch Dis Child 1972;47:854-73.

5 Rickwood AMK. The neuropathic bladder in children. In: Mundy AR, Stephenson TP, Wein AJ, eds. Urodynamics: principles, practice and applications. London: Churchill Livingstone, 1984: 326-42.

\title{
Treatment of refractory ulcerative oesophagitis with omeprazole
}

\author{
A M Dalzell, J W Searle, M K Patrick
}

\begin{abstract}
A 7 year old boy with ulcerative oesophagitis failed to respond to a two month course of intensive medical treatment using $\mathrm{H}_{2}$ receptor antagonist treatment in combination with domperidone and sucralfate. He demonstrated complete resolution using omeprazole $10 \mathrm{mg}$ once a day for eight weeks.
\end{abstract}

The aetiology of reflux oesophagitis is multifactorial. However, patients do have more frequent reflux episodes and poorer oesophageal acid clearance than normal individuals. ${ }^{1}$ Conventional medical management of oesophagitis in childhood is based on positioning and the use of pharmacological agents including $\mathrm{H}_{2}$ receptor antagonist treatment. Although the usual clinical outcome is effective resolution of symptoms, a proportion of patients with severe oesophagitis fail to respond. Omeprazole as an alternative treatment to $\mathrm{H}_{2}$ receptor antagonists has been extensively reported in adults with ulcerative oesophagitis and peptic ulcer disease, ${ }^{2}$ but not in children.

Children's Nutrition

Research Centre

The Royal Children's

Hospital Brisbane,

Herston Road, Brisbanë,

Queensland,

4029 Australia

A M Dalzell

M K Patrick

Department of

Pathology,

Royal Brisbane Hospital

J W Searle

Correspondence to:

Dr Patrick.

Accepted 14 October 1991

(Arch Dis Child 1992;67:641-2)

\section{Case report}

A 7 year old boy presented with vomiting associated with postprandial colicky abdominal pain and a weight loss of $4 \mathrm{~kg}$ in the preceding six weeks. There was a history of effortless vomiting from birth, which had not previously been investigated. Despite this, growth parameters were appropriate for age: weight 23.5 $\mathrm{kg}$ ( 50 th centile), height $119.5 \mathrm{~cm}$ ( 50 th centile), and clinical examination was unremarkable but for borborygmi and non-specific abdominal discomfort.

A blood film suggested a mild iron deficiency anaemia with a haemoglobin concentration of
$108 \mathrm{~g} / \mathrm{l}$, mean corpuscular volume $68 \mathrm{fl}$ (normal range 7-95) and mean corpuscular haemoglobin $23 \mathrm{pg}(25-30)$. Abdominal ultrasound and a barium meal and follow through were normal. Liver function tests, serum electrolyte concentrations, amylase and lipase, and urine and faeces microscopy and culture were also normal. Oesophageal manometry was not performed.

OESOPHAGEAL PH PROFILE

Oesophageal $\mathrm{pH}$ was evaluated using a $\mathrm{pH}$ sensitive antimony electrode introduced via the nares, and positioned $4 \mathrm{~cm}$ above the lower oesophageal sphincter under fluoroscopic control. Normal activity was allowed for the period of study (24 hours), and data were recorded on a solid state recorder and analysed using a computer programme (Grant Instruments (Cambridge) Ltd, Squirrel Meter/logger).

When compared with normal data taken from the work of Sondheimer and Haase, ${ }^{3}$ the results demonstrated significant and abnormal gastrooesophageal reflux. The lower oesophageal $\mathrm{pH}$ was $\mathrm{pH}<4$ for $33 \%$ of the time compared with a mean (SEM) normal of $3 \cdot 2(0 \cdot 6) \%$. There were 1.5 reflux episodes/hour compared with 0.84 $(0 \cdot 11)$, and the longest episode of $\mathrm{pH}<4$ was 64 minutes compared with $31 \cdot 6(18 \cdot 9)$.

\section{UPPER GASTROINTESTINAL ENDOSCOPY}

Upper gastrointestinal endoscopy showed circumferential ulceration and exudate in the lower third of the oesophagus. The stomach and duodenum were normal. The symptoms and oesophageal appearance did not resolve with a 12 week course of ranitidine $(75 \mathrm{mg}$ twice a day), together with domperidone (10 $\mathrm{mg}$ three times a day), and sucralfate ( $500 \mathrm{mg}$ twice a day) (fig la). Omeprazole $10 \mathrm{mg}$ once a day was 


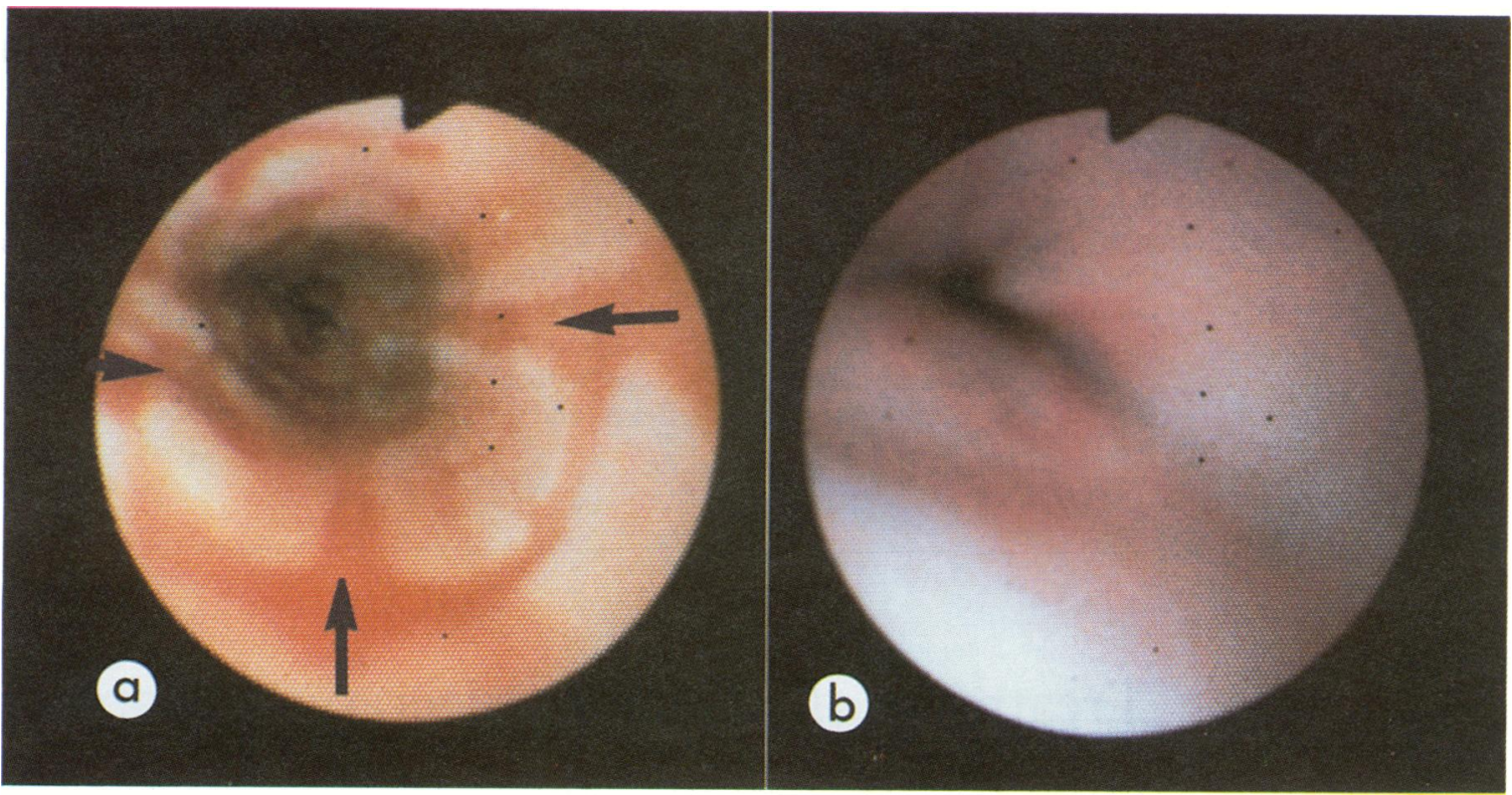

Figure 1 Lower oesophageal lumen ( $a)$ before and $(b)$ after omeprazole treatment.

started, and the patient gained symptomatic relief within three days, and demonstrated progressive weight gain. The abnormal endoscopic findings had resolved after eight weeks of treatment (fig $1 \mathrm{~b}$ ). At follow up one year later the child was asymptomatic.

\section{HISTOLOGY}

Histology of biopsy samples taken before the commencement of omeprazole treatment showed extensive ulceration with mixed fibrinous and inflammatory cell exudate covering a granulation base (fig 2a). Histology from biopsy samples taken after eight weeks of omeprazole treatment showed structurally normal oesophageal lining epithelium into which there was migration of only very occasional leucocytes (fig $2 \mathrm{~b}$ ).
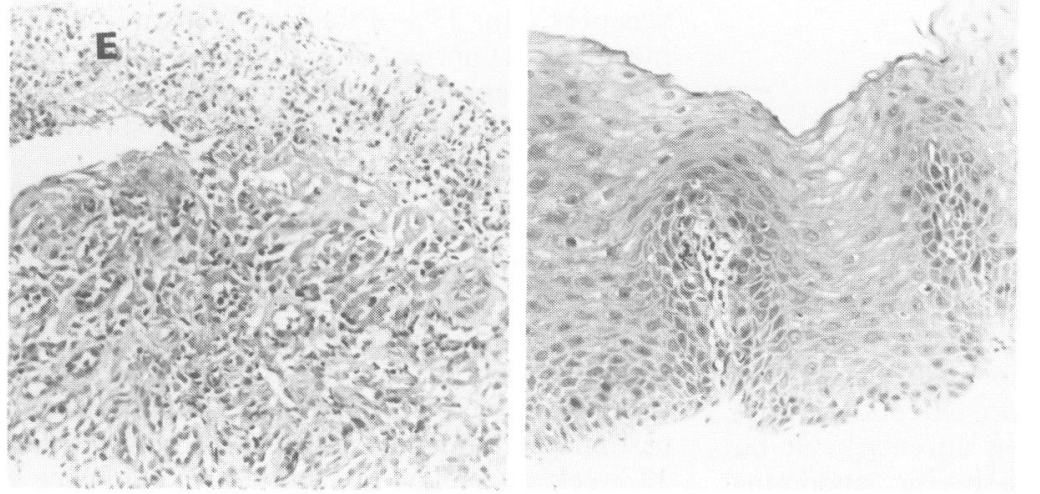

Figure 2 Oesophageal biopsy specimens (a) before omeprazole treatment showing inflammatory exudate $(E)$ covering ulcer base. (b) After omeprazole treatment showing essentially normal oesophageal lining. (Haematoxylin and eosin stain $\times 128$.)

\section{Discussion}

We have documented ulcerative oesophagitis in a 7 year old boy with significant gastrooesophageal reflux. Treatment with an $\mathrm{H}_{2}$ receptor antagonist in combination with a promotility agent and mucosal protective agent for eight weeks failed to produce any improvement. The hydrogen-potassium ATPase proton pump inhibitor, omeprazole, produced symptomatic relief within three days and effective resolution of the oesophageal lesion after eight weeks of treatment. While there is no published experience of omeprazole use in children, it is the treatment of choice for severe oesophageal ulcerative disease in adults, and is more effective in treating reflux oesophagitis than $\mathrm{H}_{2}$ receptor antagonist therapy. ${ }^{4}$ It has been used safely at doses in excess of $60 \mathrm{mg} /$ day for three years or more in patients with Zollinger-Ellison syndrome. ${ }^{5}$

Long term treatment using omeprazole is uncharted territory. While there will always be a place for surgery in severe gastro-oesophageal reflux disease, with or without oesophagitis or stricture ${ }^{6}$ we suggest that omeprazole should be considered as alternative treatment for children with ulcerative oesophagitis resistant to traditional therapy.

Dr Dalzell was the recipient of a Royal Children's Hospital Foundation Fellowship.

1 Sondheimer JM. Gastroesophageal reflux: update on pathogenesis and diagnosis. Pediatr Clin North Am 1988;35: genesis

2 Dammann HG, Blum AL, Lux G, et al. Different healing tendencies of reflux oesophagitis following omeprazole and ranitidine. Results of a German-Austrian-Swiss multicente

3 Sondheimer JM, Haase GA. Simultaneous $\mathrm{pH}$ recordings from multiple esophageal sites in children with and with out gastroesophageal reflux. F Pediatr Gastroenterol Nutr 1988;7:46-51

4 Havelund T, Laursen LS, Skoubo-Kristensen E, et al. Omeprazole and ranitidine in treatment of reflux oesophagitis: double blind comparative trial. BMF 1988;296: 89-92.

5 Lloyd-Davies KA, Rutgersson K, Solvell L. Omeprazole in Zollinger-Elisson syndrome: four-year international study. Gastroenterology 1986;90:1523.

6 Kiely EM. Surgery for gastro-oesophagel reflux. Arch Dis Child 1990;65:1291-2. 